\title{
Seasonal variability of water masses and transport on the Antarctic continental shelf and slope in the southeastern Weddell Sea
}

\author{
Jennifer A. Graham, ${ }^{1}$ Karen J. Heywood, ${ }^{1}$ Cédric P. Chavanne, ${ }^{2}$ and Paul R. Holland ${ }^{3}$ \\ Received 21 December 2012; revised 27 February 2013; accepted 25 March 2013; published 30 April 2013.
}

[1] An array of five moorings was deployed from February 2009 to February 2010 across the Antarctic shelf and slope in the southeastern Weddell Sea $\left(\sim 18^{\circ} \mathrm{W}\right)$. Observations demonstrate the key processes responsible for variability in water masses and transport in the region. Rapid fluctuations in temperature and salinity throughout the year are linked with variability in wind stress over the array. This causes the deepening or shoaling of the pycnocline, past the depth of the moorings. In the upper $500 \mathrm{~m}$, the seasonal cycle in salinity shows freshening in autumn, with the strongest freshening at the shallowest mooring ( $\sim 250 \mathrm{~m})$, furthest on-shelf. The sea ice concentration over the array exceeds $90 \%$ during this period and contributes a positive salt flux into the ocean during autumn.

Freshening begins during strong along-shore (easterly) winds in late April 2009. This demonstrates that variations in Ekman transport and wind-driven mixing play a key role in determining the salinity of shelf waters around Antarctica. Transport of the Antarctic Slope Current also shows a seasonal cycle with a maximum during late April. Model simulations show the importance of along-shore advection, as the arrival of a fresh anomaly from upstream determines the timing of the salinity minimum at the array. These processes are likely to be important for other regions around the Antarctic continent.

Citation: Graham, J. A., K. J. Heywood, C. P. Chavanne, and P. R. Holland (2013), Seasonal variability of water masses and transport on the Antarctic continental shelf and slope in the southeastern Weddell Sea, J. Geophys. Res. Oceans, 118, 2201-2214, doi:10.1002/jgrc.20174.

\section{Introduction}

[2] Antarctic continental shelves play a key role in the global ocean circulation. First, basal melting of ice shelves may occur, adding freshwater to the ocean, and in places accelerating glacier flow [Pritchard et al., 2012]. Second, the coldest, densest water found on the continental shelves subsequently forms Antarctic Bottom Water (AABW). This water mass provides the bottom limb of the global meridional overturning circulation, determining the global rates of heat and freshwater transport [Talley, 2003].

[3] In the Weddell Sea, sources of bottom water are primarily found in the southern and western sides of the basin, where the continental shelves are wider [e.g., Fahrbach et al., 1994]. In contrast, continental shelves in the southeastern Weddell Sea are narrower, preventing the formation of a cold, dense water mass. While AABW does not form in this region, the westward transport along the shelf break associated with the

\footnotetext{
${ }^{1}$ School of Environmental Sciences, University of East Anglia, Norwich, UK.

${ }^{2}$ Institut des sciences de la mer de Rimouski, Université du Québec à Rimouski, Rimouski, QC, Canada.

${ }^{3}$ British Antarctic Survey, Cambridge, UK.

Corresponding author: J. A. Graham, School of Environmental Sciences, University of East Anglia, Norwich, NR4 7TJ, UK. (j.graham@uea.ac.uk)

(C)2013. American Geophysical Union. All Rights Reserved. 2169-9275/13/10.1002/jgrc.20174
}

Antarctic Slope Front (ASF) allows the shelf waters from this region to influence the properties of AABW formed downstream [Thoma et al., 2006]. Prevailing easterly winds around the Antarctic continent lead to onshore Ekman transport of cold, fresh surface waters onto the continental shelf. Offshore, the warmer, saltier Warm Deep Water (WDW) is found beneath the surface waters. The boundary between these two water masses, at the shelf break, forms the ASF, and the dynamics of this front determine the transport of heat and freshwater across the shelf and slope [Chavanne et al., 2010]. In the eastern Weddell Sea, the narrow continental shelves mean that the ice shelves are closer to the shelf break than they are in regions such as the southern Weddell Sea; therefore, they may be more sensitive to changes occurring in the ASF and across-slope transport [Nicholls et al., 2006; Thoma et al., 2006; Nøst et al., 2011].

[4] Historically, there has been a lack of observations around the Antarctic continent, compared with lower latitudes, with ice cover and meteorological conditions leading to a bias toward observing in summer. This means that we have little evidence for how the water mass properties and transport in these high latitudes may vary throughout the year. While models may be used to investigate climate variability in the region, there is a critical shortage of data with which to validate such models, especially in winter. It is essential that climate models simulate the correct exchange of waters on and off the continental shelf if we are to accurately predict the strength of the AABW 
overturning cell or the melting of the Antarctic ice shelves [Hellmer et al., 2012]. Inaccurate seasonal cycles in the models would lead to incorrect water mass formation under future forcing scenarios.

[5] Previous studies have demonstrated the importance of surface wind forcing for determining water mass variability on the continental shelves in the eastern Weddell Sea. Ohshima et al. [1996] showed that freshening on the continental shelf occurs during autumn in East Antarctica (LützowHolm Bay). This freshening was attributed to seasonal strengthening of along-shore winds, leading to onshore Ekman transport of the fresh surface layer that forms during summer. At the Greenwich Meridian, Núñez-Riboni and Fahrbach [2009] used moored current and temperature observations between 1996 and 2005, along with a series of ship transects, to identify four mechanisms responsible for transport variability in the Antarctic Slope Current (ASC). (In the eastern Weddell Sea, the narrow continental shelves cause the Antarctic Coastal Current and the ASC to merge. The transport associated with the ASC (discussed in this paper) is then the same feature referred to as the Antarctic Coastal Current by NúñezRiboni and Fahrbach [2009].) The seasonal cycle was primarily governed by Ekman transport, with increased along-shore winds and sea ice drag on the surface causing a maximum transport in autumn. Other mechanisms that play a role in the variability are Sverdrup transport, thermohaline forcing, and thermal wind balance.

[6] Recently, Nøst et al. [2011] have used temperature and salinity observations from tagged southern elephant seals on the shelf in the eastern Weddell Sea to investigate transport of heat and freshwater across the ASF during FebruaryOctober 2008. They argued that due to the low temperatures found on the shelf, the freshness of shelf waters in the eastern Weddell Sea can be primarily attributed to the prevailing easterly winds and onshore Ekman transport rather than meltwater contributions. They show that eddy fluxes are responsible for onshore transport of WDW. However, this WDW is not warm enough to provide the required freshwater input from basal melting [Nøst et al., 2011].

[7] Here we present the first yearlong time series of transport, temperature, and salinity from moorings on the shelf and slope in the southeastern Weddell Sea $\left(\sim 18^{\circ} \mathrm{W}\right)$. We discuss the oceanic seasonal cycle evident from this new data set and determine the processes responsible for such variability. Model simulations are used to support our conclusion that conditions at the mooring array are strongly influenced by advection of shelf waters from upstream. The moored instruments are outlined in section 2. Water masses present above the shelf and slope are identified in section 3 . Their variability is investigated in section 4, including comparison with results from a model simulation of the region. The transport through the mooring array is presented in section 5. Discussion of the results and final conclusions are presented in sections 6 and 7, respectively.

\section{Observational Data}

[8] An array of five moorings (M1-M5) was deployed on the Antarctic continental shelf and slope across the ASF in the southeastern Weddell Sea $\left(\sim 18^{\circ} \mathrm{W}\right)$, recording temperature, salinity, and current velocity from February 2009 to February 2010 (Figure 1a). These observations formed a
UK contribution to the multinational Synoptic Antarctic Shelf-Slope Interactions (SASSI) study [Heywood et al., 2012]. The array spans a cross-shore distance of approximately $50 \mathrm{~km}$, from the shallowest mooring on the shelf in a water depth of $273 \mathrm{~m}$, to the deepest offshore mooring at a depth of $2600 \mathrm{~m}$. The results discussed in this paper were obtained from conductivity-temperature-pressure sensors (SBE 37) and upward looking acoustic Doppler current profilers (ADCPs; RDI), fitted on each of the five moorings, along with current meters (Nortek Aquadopp) fitted on M4 and M5 (Figure 1b). The uppermost sensors were typically at depths $>400 \mathrm{~m}$ to reduce the risk of iceberg impact.

[9] At mooring M1, the SBE-37 pressure sensor was calibrated using the depth measured by the ship echo sounder at the deployment location and the mooring design (which accounted for cable stretching). At moorings M2-M5, a more precise calibration procedure was available due to the upward-looking $75 \mathrm{kHz}$ ADCPs detecting the sea surface. The depths of the ADCPs were determined following the method of Visbeck and Fischer [1995]. The depths of the SBE-37 sensors were then obtained using the mooring designs. The applied pressure offsets ranged from 1 to 70 dbar. Once the SBE-37 pressure sensors were calibrated, the temperature and salinity data were calibrated using CTD profiles from the deployment and recovery cruises (ES033 and JR248, respectively). Uncertainties in the salinity measurements arise predominantly from a combination of the pressure offsets and thermohaline variability in the region. As such, the largest salinity uncertainties are found at M1 $( \pm 0.02)$, whereas all other sensors have uncertainties less than \pm 0.005 . Mooring knock-down occurred during strong current events, causing depth increases of up to $31 \mathrm{~m}$ for the ADCP on top of the deepest mooring. The ADCP currents were therefore gridded onto constant depth levels using linear interpolation in the vertical direction.

[10] Wind velocity was obtained from the National Centers for Environmental Prediction Climate Forecast System (NCEP CFS) reanalysis [Saha et al., 2010]. Variability in the NCEP CFS reanalysis data compares well with observations at Halley and Neumayer weather stations, which are both located on ice shelves in the eastern Weddell Sea (Brunt and Ekström ice shelves, respectively). However, since these observations are used to create the reanalysis, they should not be considered as an independent quality control. Wind velocity fields on a $0.5^{\circ} \times 0.5^{\circ}$ grid, at 6 hourly intervals, were averaged into daily mean observations and rotated into along-shore and across-shore components (rotating clockwise by $139^{\circ}$ ). Daily sea ice concentration was obtained from the Advanced Microwave Scanning Radiometer-Earth Observing System (AMSR-E) on a $6.5 \mathrm{~km}$ grid [Spreen et al., 2008]. Monthly cumulative salt flux data were obtained on a $25 \mathrm{~km}$ grid using estimates of thin ice thickness inferred from satellite observations [Tamura et al., 2011]. This salt flux accounts for ice production in thin ice thickness areas (e.g., polynyas and divergent ice fields).

\section{Water Masses Observed on the Continental Shelf and Slope}

[11] The temperature and salinity observations show the presence of cold, freshwater on the shelf (Figure 2a). Warmer, saltier water occurs at greater depth on the slope 
(a)

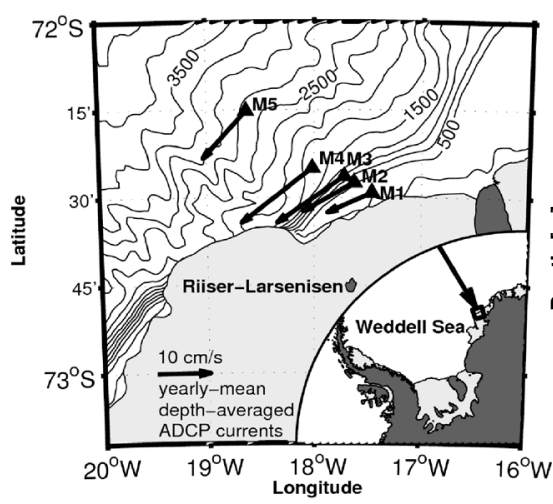

(b)

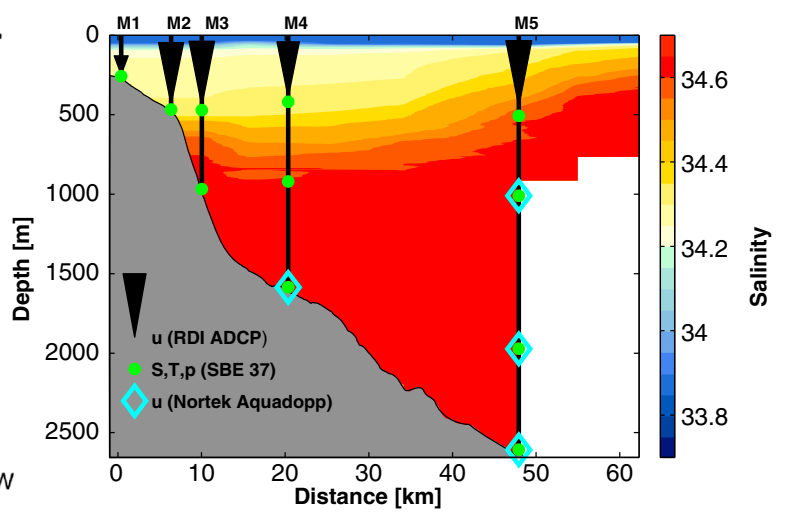

Figure 1. (a) Location of moorings and yearly mean currents for each mooring. Contours and gray shading show the bathymetry (250 m intervals) and ice shelf extent, respectively (from GEBCO). (b) Location of ADCP, SBE-37, and Nortek Aquadopp instruments on each of the five moorings. Colored contours show the salinity section observed during the deployment cruise (ES033), February 2009.

and farther offshore. Specific water masses are identified following Nicholls et al. [2009a]. The fresher water mass observed on the shelf is known as Eastern Shelf Water (ESW). Winter Water (WW) is also observed on the shelf and slope, characterized by its temperature minimum, and exhibiting higher salinity values than ESW (due to winter ice production). Above the slope, M2-M4 show the presence of Modified Warm Deep Water (MWDW), which lies on the mixing line between WW and WDW (Figure 2a). WDW is also found at M3 and M4 at depths 900-1000 m (Figures 2a, 2e, and 2g). At M5, the shallowest mooring shows the presence of WDW, whereas the deepest observations, at both M4 and M5 (depth $>1500 \mathrm{~m}$ ), show the presence of Weddell Sea Deep Water (WSDW).

[12] Moored sensors that show the largest range for both temperature and salinity typically lie in the pycnocline, in the transition between WW and WDW, at depths 400-1000 m. Vertical movement of the pycnocline can account for the high-frequency (submonthly time scale) fluctuations in water mass properties seen in Figures $3 \mathrm{a}$ and $3 \mathrm{~b}$ (particularly for M2-M4). Intrusions of MWDW are found for the shallowest mooring, on the shelf at $256 \mathrm{~m}$, during August-September, with temperatures reaching $-1.2^{\circ} \mathrm{C}$ (Figures 2b).

[13] A seasonal cycle is evident on the shelf, where salinity decreases by $\sim 0.2$ during autumn before gradually increasing through the winter (Figure 3b). A minimum daily mean salinity of 34.13 occurs in early June, and a maximum of 34.39 occurs in late February 2009. Temperature at M1 remains close to surface freezing for the majority of the year, but also decreases during autumn, with a minimum of $-1.88^{\circ} \mathrm{C}$ in late July (Figure 3a). Temperature and salinity at $\sim 500 \mathrm{~m}$ (M2-M4) show a similar seasonal cycle to that of M1, but both reach a minimum slightly later, in July or August. For the shallowest sensor on M5, cooling and freshening does occur during autumn and winter, but the minimum values for the year are actually found during the preceding summer.

[14] For water masses found beneath the pycnocline, there is a small seasonal variability. WSDW has a salinity range of 234.66-34.67 (Figure 2a), with observations at M5-2578 m showing a minimum in March and a maximum in July. A similar cycle is found for temperature at this location. This seasonality shows the opposite trend to the water mass above the thermocline. Some variability may exist due to vertical movement of isopycnals or mixing with overlying WDW. WDW is more saline, with salinity values reaching $\sim 34.7$ and maximum temperatures $\sim 0.86^{\circ} \mathrm{C}$ (M5-478 m; Figure 2i). The seasonality of sensors in the WDW depth range is less clear than that for other water masses; however, for observations at M5-980m, there is typically less highfrequency variability during late winter-spring (AugustNovember; Figure 2j) than during the rest of the year. The possible causes of observed variability are addressed in the following section.

\section{Mechanisms for Observed Variability}

\subsection{High-Frequency Variability}

[15] The high-frequency (submonthly) fluctuations in temperature and salinity evident above the slope (Figures 2 and 3 ) occur as the pycnocline moves up and down past the moored sensors. Changes in wind stress curl cause the shoaling or deepening of isopycnals through upwelling or downwelling. For example, during October 2009, observations at $963 \mathrm{~m}$ on M3 show cooling and freshening (Figures $3 \mathrm{a}$ and $3 \mathrm{~b}$ ) due to the presence of MWDW rather than WDW (Figures 2a and 2e). During this time, along-shore winds (easterly) and negative wind stress curl over the array (Figures 3c and 3d) lead to onshore Ekman transport and downwelling above the continental slope. This causes deepening of isopycnals, so MWDW is present at increased depths on the slope. At the same time, the moored sensors between 400 and $500 \mathrm{~m}$ (M2-M4) show reduced variability, as they then lie above the pycnocline.

[16] Shoaling of the pycnocline is indicated by increased temperature and salinity at the $400-500 \mathrm{~m}$ sensors. This occurs during periods of either reduced or positive wind stress curl, when the along-shore winds are either reduced or reversed (Figures 3a-3d). For example, the greatest increase in temperature and salinity is observed during January-February 2010 at $405 \mathrm{~m}$ for M4 (Figure 2f). Similar changes are also observed at M2 and M3 during this time 

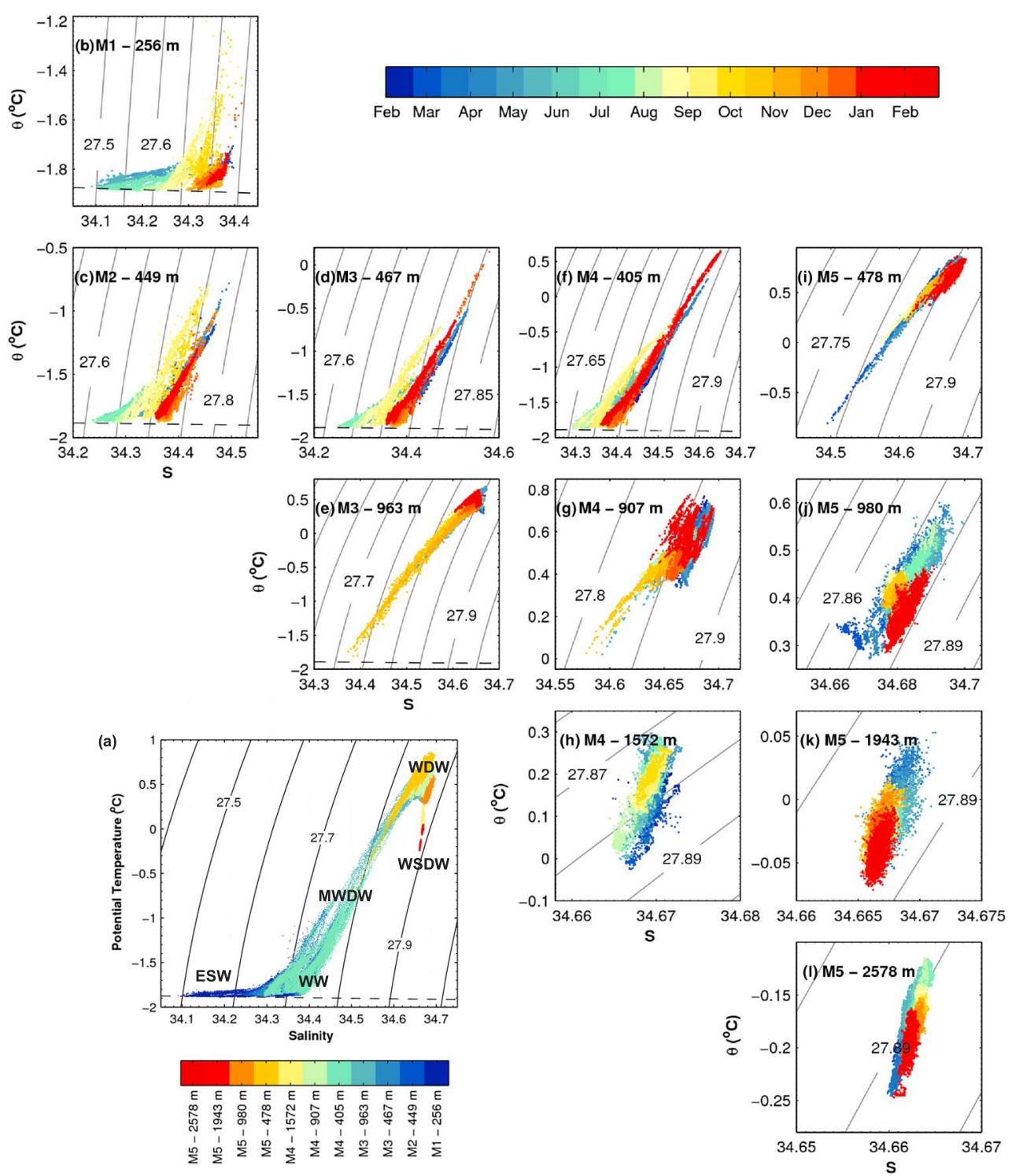

Figure 2. Potential temperature ( $\theta$ )-salinity (S) diagrams for (a) all of the mooring observations, with colors indicating location of each mooring, and water masses identified following Nicholls et al. [2009a]; and (b-k) each mooring, colored by time of observation (tick marks indicating the start of each month). Gray contours show potential density, with varying intervals for each panel. Black dashed line shows the surface freezing temperature, varying with salinity. Note that the axis limits for $S$ and $\theta$ vary, having been optimized for each mooring panel.

(Figures $2 \mathrm{c}$ and $2 \mathrm{~d}$ ). For the majority of the year, the pycnocline is below $270 \mathrm{~m}$ at the shelf break, preventing transport of MWDW onto the shelf. However, warm intrusions of MWDW are found at M1 during August-September 2009 (Figure 2b). This occurs as westerly along-shore winds cause offshore Ekman transport above the continental shelf and slope, and wind stress curl leads to upwelling (Figures 3c and 3d). Whenever the pycnocline shoals, the observations at greater depth $(>500 \mathrm{~m})$, as well as the shallowest sensor at M5, show reduced variability, as they then lie below the pycnocline.

[17] Although these examples provide strong evidence for wind-driven deepening and shoaling of the pycnocline, other processes must be considered. For example, baroclinic eddies have been shown to be important for transport of properties across the ASF [Nøst et al., 2011]. Also, any vertical movement of the pycnocline will propagate along the coast as Kelvin waves or coastally trapped waves. Therefore, nonlocal forcing will influence changes observed at the array. A more detailed analysis of high-frequency variability at the array will be the subject of a separate paper.

\subsection{Seasonality on the Continental Shelf}

[18] The greatest seasonality is observed for the salinity of the cool, fresh shelf water. We focus our attention on M1, where freshening of $\sim 0.2$ is observed, beginning during April 2009. The mean sea ice concentration over the mooring array exceeds $90 \%$ during this freshening (Figure $3 \mathrm{e}$ ). Polynya salt fluxes inferred from satellite observations and reanalysis [Tamura et al., 2011] are positive, adding salt to 
(a)
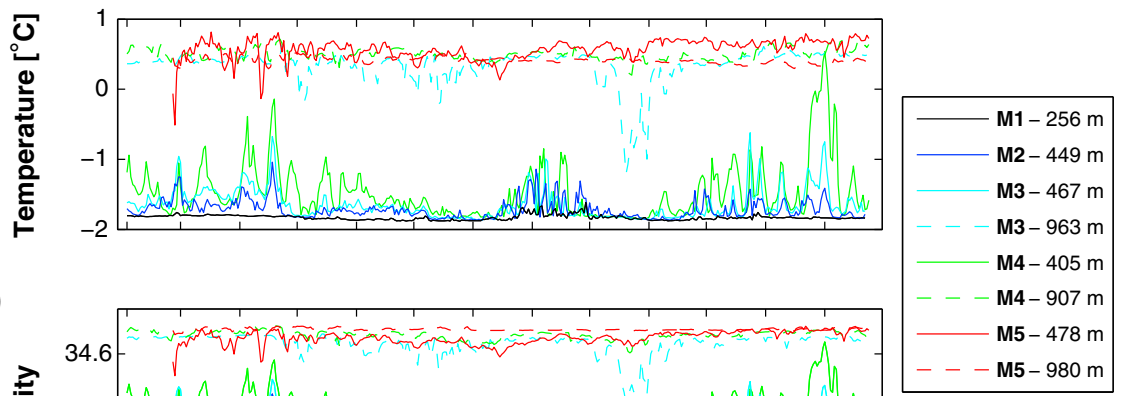

(b)

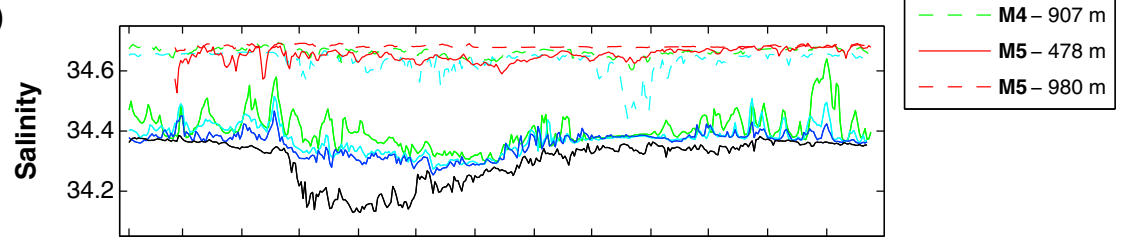

(c) $T_{i \infty}$

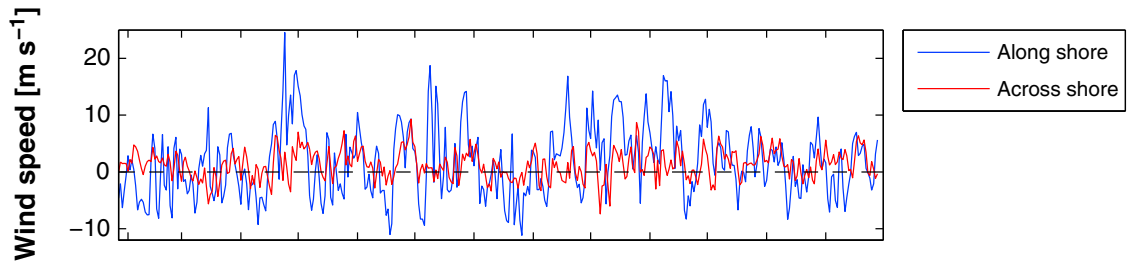

(d)

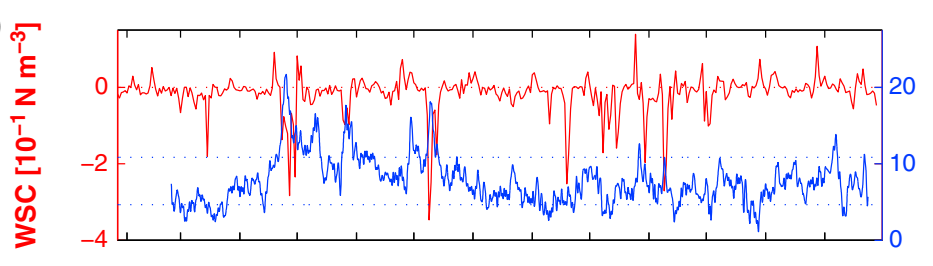

(e)

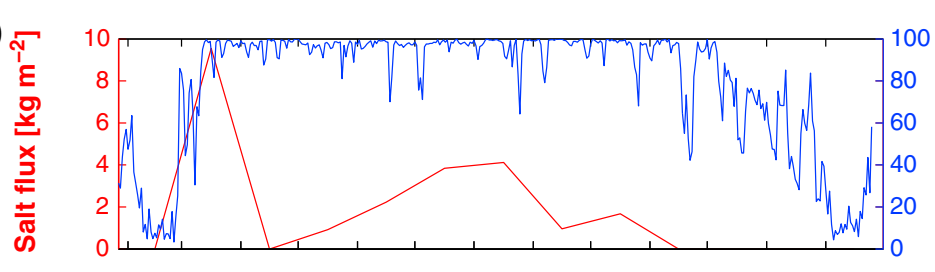

(f)

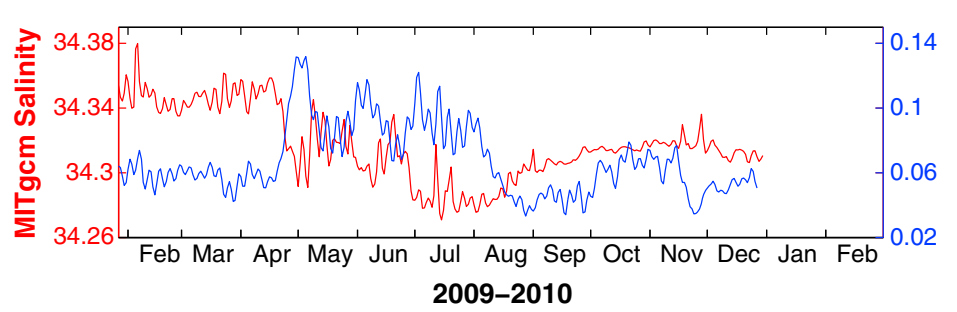

Figure 3. Daily mean (a) potential temperature $\left[{ }^{\circ} \mathrm{C}\right]$ and (b) salinity at moorings $\mathrm{M} 1-\mathrm{M} 5$ for depths $<1000 \mathrm{~m}$ (for locations, see Figure 1). (c) Daily mean wind velocity from NCEP CFS reanalysis, along-shore and across-shore (easterly and southerly, respectively) at the mooring location (average over $16^{\circ} \mathrm{W}-20^{\circ} \mathrm{W}$, $71.5^{\circ} \mathrm{S}-72.5^{\circ} \mathrm{S}$ ). Positive values indicate winds from east and south, respectively. (d) Total hourly transport perpendicular to the mooring array [Sv] and daily wind stress curl (WSC) over the mooring array $\left(16^{\circ} \mathrm{W}-20^{\circ} \mathrm{W}, 71.5^{\circ} \mathrm{S}-72.5^{\circ} \mathrm{S}\right)\left[10^{-1} \mathrm{~N} \mathrm{~m}^{-3}\right]$. Dotted blue lines indicate "high" and "low" limits $( \pm 1$ standard deviation) for ASC transport. Dotted red line indicates zero WSC. (e) Monthly cumulative salt flux into the ocean $\left[\mathrm{kg} \mathrm{m}^{-2}\right]$ and daily sea ice concentration [\%]. Salt flux data are calculated on a $25 \mathrm{~km}$ grid, deduced from sea ice production data inferred from satellite observations [Tamura et al., 2011]. Sea ice concentration has been obtained from Advanced Microwave Scanning Radiometer-EOS (AMSR-E) observations on a $6.5 \mathrm{~km}$ grid [Spreen et al., 2008]. The gridded sea ice data have been averaged over the mooring array. (f) Salinity and current speed at $250 \mathrm{~m}$ at the M1 location in the MITgcm simulation for 2009 (the grid point indicated by the green cross in Figure 5). Currents have been smoothed using a 7 day running mean. 
(a) Salinity at M1
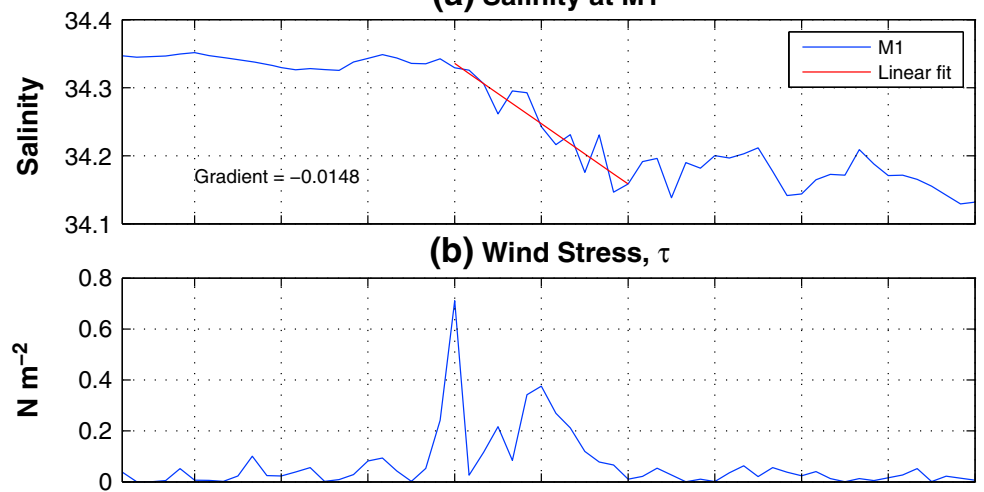

(c) Along-stream, $\mathrm{U}\left[\mathrm{m} \mathrm{s}^{-1}\right]$

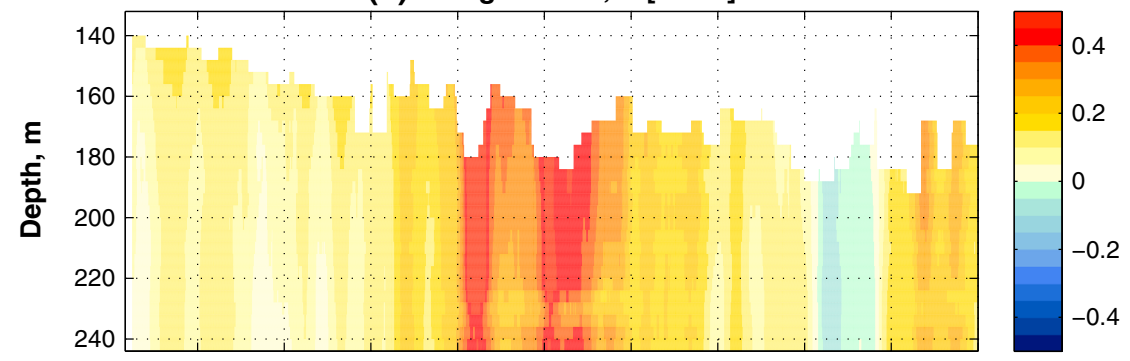

(d) Across-stream, $\mathrm{V}\left[\mathrm{m} \mathrm{s}^{-1}\right]$

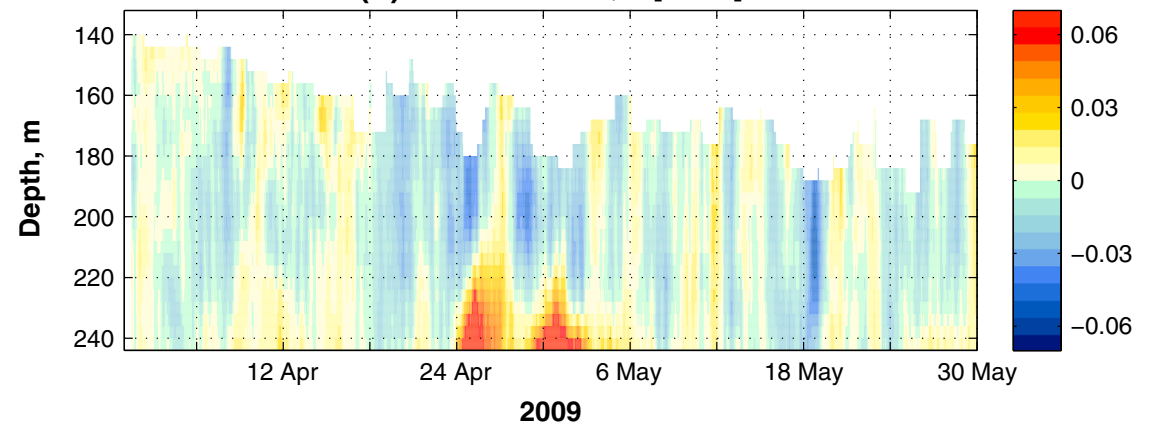

Figure 4. Conditions at M1 for April-May 2009. (a) Daily mean salinity at M1-273 m (blue). Red line shows the linear fit (using least squares regression) for 24 April to 6 May, the period of most rapid freshening, with a gradient of $0.0148 \mathrm{psu} / \mathrm{d}$. (b) Along-shore surface stress, $\tau$, calculated using Nøst et al. [2011, equation (A18)], using wind fields shown in Figure 2c and an ice concentration of 90\%. (c) Along-stream and (d) across-stream ADCP velocity from M1-273 m. Components have been calculated relative to the mean direction of the depth-averaged current at M1 for the year of observations (February 2009 to February 2010; Figure 1a). Positive values correspond to downstream and offshore directions. ADCP data have been smoothed using a 24-hour running mean.

the ocean, during autumn and winter. The maximum salt flux occurs in March, prior to freshening, coinciding with the growth of sea ice during this time (Figure 3e). Therefore, local surface freshwater fluxes cannot account for this change in salinity at depth.

[19] The freshening on the continental shelf begins during a period of strong, along-shore winds, with peak speeds $>20 \mathrm{~m} \mathrm{~s}^{-1}$ on 24 April (Figures 3c, 4a, and 4b). This along-shore wind forcing could have three major impacts on the ocean: (1) increased mixing, deepening the fresh surface mixed layer; (2) onshore Ekman transport, thickening the upper, fresher layer on the shelf; and (3) advection of a salinity anomaly from the east, with a wind-driven anomaly in the mean along-shore flow. The potential for the wind to change the salinity by each of these three mechanisms is now assessed in turn.

\subsubsection{Wind-Driven Mixing}

[20] The potential for wind to increase the mixed layer depth depends on local stratification, but temperature and salinity on the shelf are only known at the mooring, at the base of the water column. We use the salinity profile measured at the M1 location in February 2009 (Figure 1b) to calculate that the resultant salinity for a fully mixed water column would be 34.19 , higher than the salinity minimum at M1 (34.13 \pm 0.02 ; Figure $3 b)$. The difference between these values is outside the range of uncertainty for M1. The depth-averaged value of 34.19 is also likely to be an underestimate since it does not take into account the addition of salt from the increasing ice concentration between February and March (Figure 3e). The salt flux of $9.55 \mathrm{~kg} \mathrm{~m}^{-2}$ estimated from thin ice formation during March 2009 would increase the depth-averaged salinity by $\sim 0.03$. 
Therefore, while the winds may be able to increase the depth of the mixed layer, it is not possible for wind-driven mixing to be the sole cause of the freshening at M1.

\subsubsection{Ekman Transport}

[21] Nøst et al. [2011] proposed a conceptual model where the salinity on the shelf is influenced by two opposing overturning circulations. Ekman overturning brings freshwater onto the shelf in the surface layer, whereas eddy overturning brings more saline water onto the shelf in the bottom layer. Using this model, we assess the potential for local Ekman transport to decrease the salinity on the shelf (neglecting along-shelf advection for the moment). If the rate of change of salinity was determined purely by local overturning Ekman transport, then it can be calculated using the following equation:

$$
W H \frac{\mathrm{d} S_{\mathrm{da}}}{\mathrm{d} t}=V_{\mathrm{ek}}\left(S_{s}-S_{b}\right)
$$

where $W$ and $H$ are the width and depth of the continental shelf, and $S_{\mathrm{da}}, S_{s}$, and $S_{b}$ are the depth-averaged, surface, and bottom salinity values, respectively. The Ekman transport, $V_{\text {ek }}$, is defined as positive toward the coast and is proportional to the wind stress, $\tau$, calculated using equation (A18) from Nøst et al. [2011], which takes into account the effect of sea ice concentration on the momentum transfer between the atmosphere and the ocean.

[22] The wind stress felt at the ocean surface is dependent on the sea ice concentration, such that the drag exerted on the ocean will increase as the sea ice initially increases. However, once the sea ice concentration increases to a point where the ice can no longer move freely on the surface, this reduces the force exerted on the ocean, so the drag coefficient decreases. A maximum drag is then felt when the sea ice concentration is approximately 60-80\% [e.g., NúñezRiboni and Fahrbach, 2009; Nøst et al., 2011]. For this study, we follow the assumption made by Nøst et al. [2011, equation (A18)], so the maximum drag is felt at $80 \%$ sea ice concentration.

[23] According to equation (1), the rate of change of salinity on the shelf is proportional to both the Ekman transport and the salinity difference between the surface and the bottom of the water column. For example, if the water column were fully mixed $\left(S_{s}=S_{b}\right)$, then the overturning transport could have no impact on salinity, irrespective of the wind stress. It is for this reason that Ekman transport may have the greatest impact in autumn, following the development of a fresh surface layer during summer. We make the assumption that changes observed at M1 (256 m) are representative of changes for the whole water column. During the period of most rapid freshening (24 April to 6 May), the average wind stress is $0.20 \mathrm{~N} \mathrm{~m}^{-2}$ (assuming an ice concentration of $90 \%$; Figures $4 \mathrm{~b}$ and $3 \mathrm{e}$ ). During this time, the salinity at M1 experiences a freshening rate of $0.015 \mathrm{psu} / \mathrm{d}$ (deduced from a least squares straight-line fit to the M1 time series between 24 April and 6 May; Figure 4a). The width and the depth of the continental shelf at M1 are taken to be $5 \mathrm{~km}$ and $273 \mathrm{~m}$, respectively, chosen as the distance from the M1 location to the ice shelf and the depth at the mooring location. Using these values, the necessary salinity difference is found to be 0.17 , giving an upper limit for surface salinity of 34.18. Observations from a Weddell seal tag offshore $\left(19.2^{\circ} \mathrm{W}, 72.1^{\circ} \mathrm{S}\right)$ on 9 April 2009 [Nicholls et al., $2009 \mathrm{~b}$ ] indicate that the offshore surface salinity is indeed less than this value, with an average salinity value of 33.96 in the top $40 \mathrm{~m}$.

[24] A number of assumptions have been made in this calculation. In assuming that the sea ice concentration is $90 \%$, the surface drag coefficient has been approximated using the method described by Nøst et al. [2011]. However, without direct observations of the ice motion, we cannot know the true surface drag above the mooring array. A large source of uncertainty comes from the values chosen for $W$ and $H$. These values specify the volume of ocean over which the overturning occurs. The chosen values refer to the box between the ice shelf and the M1 location [ice shelf limits taken from General Bathymetric Chart of the Oceans (GEBCO)]; however, it is possible that the limit of the overturning cell does not coincide with the ice front, and therefore, this might not be the correct volume. Quantifying the uncertainty of these values is difficult; however, we estimate that the total uncertainty, including each of the terms in equation (1), is $\pm 60 \%$. The required salinity difference is then $0.17 \pm 0.10$, giving an upper limit for the surface salinity of $34.18 \pm 0.10$. While this range of upper limits is still above the value observed by the seal tag offshore, perhaps a larger source of uncertainty arises from the assumption that the changes observed at M1 are representative of the depthaveraged salinity changes. Onshore Ekman transport and the resulting deepening of the fresh upper layer cause deepening of the halocline. If the halocline was as close to the surface in April 2009 as it was in February 2009 (Figure 1b), then the depth-averaged salinity changes due to the deepening of the halocline would be greater than the bottom salinity changes observed at M1, requiring a larger surface-tobottom salinity difference than estimated. The offshore profile from the Weddell seal tag suggests there is little change in the depth of the halocline between February and April. However, we have no observations to confirm the depth of the halocline farther onshore, above the shelf. Therefore, although we estimate it to be possible that Ekman transport could account for the observed freshening, there is considerable uncertainty in this estimation.

[25] Evidence for onshore transport may be provided from ADCP observations at M1 (Figures 4c and 4d). During the strongest winds (24 April to 6 May), there are increases in both along-stream and onshore transport in the upper range of the ADCP data. At M1, offshore transport also increases at depths $>220 \mathrm{~m}$, consistent with a bottom Ekman layer. This offshore transport freshens the shelf waters, because the more saline water at the base of the water column is replaced by fresher water in the upper layer. The onshore transport is observed at depths greater than $180 \mathrm{~m}$, presumably below the depth of the surface Ekman layer, suggesting that a simple model which considers transport only in the surface and bottom Ekman layers may be invalid. However, the current has been decomposed relative to the mean alongstream direction at M1. If the current meanders, this would then contribute to the observed across-stream transport.

[26] At M1, the depth-average across-stream velocity is positively correlated with salinity at $273 \mathrm{~m}$. Across-stream velocities are taken to be positive in the offshore direction, so this correlation indicates that freshening is associated with onshore transport. At the base of the ADCP 
observations ( $240 \mathrm{~m})$, velocity is negatively correlated, so onshore transport is associated with increased salinity. However, neither of these correlations are statistically significant. Farther offshore, the correlation between depth-averaged, across-stream ADCP velocities and salinity at M4 and M5 becomes significant and negative (with $|R|>0.1$ ). A similar correlation is also found here between velocity and temperature. Therefore, transport in the upper $500 \mathrm{~m}$ at M4 and M5 typically brings warmer, saltier water toward the shelf. The difference between correlations observed at M1 and the offshore moorings is likely due to the depth of the pycnocline shoaling in the offshore direction and lying above the depth of the ADCP at M5 (Figure 1b). At M4 and M5, onshore velocities may then bring increased volumes of MWDW toward the shelf.

\subsubsection{Advection From the East}

[27] Until now, we have only discussed the cross-shelf influence on the salinity at M1. The influence of along-shore advection was not included in the Nøst et al. [2011] model, since they consider average properties over a large stretch of coast. However, we now consider the along-shore freshwater transport, which will likely influence a two-dimensional, cross-shelf section. To investigate possible sources of freshwater upstream of the moorings, we use the MITgcm (Massachusetts Institute of Technology general circulation model) ocean, sea ice, and ice shelf models [Marshall et al., 1997; Losch, 2008; Losch et al., 2010] forced by the National Centers for Environmental Prediction Climate Forecast System (NCEP CFS) reanalysis [Saha et al., 2010]. The model is run for 1979-2010 after a 9 year spin-up at a resolution of $0.25^{\circ}$ longitude (about $8 \mathrm{~km}$ at $\mathrm{M} 1$ ) for the entire Southern Ocean (south of $30^{\circ} \mathrm{S}$ ). Iceberg calving and melt are crudely parameterized by applying a uniform and steady freshwater flux along the Antarctic coastline [Stammer et al., 2004].

[28] On the shelf at the location of the SASSI array, at $\sim 250 \mathrm{~m}$, the model salinity is lower than that observed (Figures $3 \mathrm{~b}$ and 3f). However, as we are investigating the variability rather than the mean conditions, this model proves to be useful. The model reproduces the initial freshening response on the shelf, with a salinity decrease at $\sim 250 \mathrm{~m}$ in April (Figure 3f). After this initial freshening, the salinity increases briefly before freshening to a minimum at the M1 location in July, 1 month later than observed. A fresh anomaly develops $\sim 600 \mathrm{~km}$ east of the array during the preceding summer $\left(0^{\circ} \mathrm{W}-6^{\circ} \mathrm{W}\right.$; Figure 5$)$ and propagates along the coast to the mooring, covering $600 \mathrm{~km}$ in 3 months $\left(\sim 0.07 \mathrm{~m} \mathrm{~s}^{-1}\right)$. This is consistent with advection by model velocities during this time (Figure 3f). These velocities are considerably smaller than those observed at M1, but they do have a similar peak during the initial freshening event (Figure 3f). Between 24 April and 6 May, velocities observed at M1 exceed 0.3 $\mathrm{m} \mathrm{s}^{-1}$ (Figure 4c), sufficient to advect freshwater by 300 $\mathrm{km}$ within 2 weeks. This difference in speed would account for the difference in timing of the salinity minima between the model and observations.

[29] The freshening upstream in the model, adjacent to the Fimbul Ice Shelf $\left(\sim 0^{\circ} \mathrm{W}-5^{\circ} \mathrm{W}\right)$, originates from sea ice melt during the preceding summer (Figure 6). Examination of other years in the simulation indicates that this may be a regular feature, due to the seasonal sea ice retreat. By late summer, the sea ice edge, as well as increased freshwater flux into the ocean, is close to the continental shelf and coastal current in this region. Along-shore winds during autumn can then result in onshore Ekman transport, leading to an increased sea surface slope and associated geostrophic alongshore flow anomaly. This hastens the arrival of freshwater from upstream (Figures 3 and 4). The mean model sea ice field differs in detail from that observed (Figures 6 and 7), but the regional reduction of sea ice and the associated freshwater flux into the ocean are consistent with both AMSR-E observations and polynya salt fluxes inferred from satellite observations and reanalysis [Tamura et al., 2011].

[30] The model shows that although the increased wind stress and resultant Ekman transport cause the initial freshening at the SASSI location, advection of freshwater from upstream aids the persistence of the fresh anomaly and can ultimately determine the timing of the salinity minimum (Figure 5). Downstream of the moorings, the salinity minimum occurs later in the year, consistent with advection from upstream.

[31] After the fresh anomaly has passed the SASSI array, the observed salinity on the shelf and slope gradually increases (Figure 3b). The salinity increase is too rapid for polynya salt fluxes at the surface to account for the change. Salinity at M1 increases by 0.23 over 4 months (JuneSeptember). Assuming that this change is representative of the water column, a salt flux of approximately $60 \mathrm{~kg} \mathrm{~m}^{-2}$ would be needed. The cumulative salt flux of $11 \mathrm{~kg} \mathrm{~m}^{-2}$, estimated by Tamura et al. [2011] (Figure 3e), is much lower than this value. Although these salt fluxes do not account for ice formation occurring in ice-covered regions [Tamura et al., 2011; Arthun et al., 2013], and our estimation of the necessary salt flux does not take into account the effect of shoaling isopycnals, the difference suggests that mixing with a more saline, offshore water mass is necessary. During AugustSeptember 2009, intrusions of MWDW are observed at M1 (Figure 2b). This provides evidence for an additional salt flux from offshore. Nøst et al. [2011] showed that eddy overturning is responsible for increasing the salinity of shelf waters. Their observations show that the eddy salt flux onto the shelf is greater than the flux from brine rejection during March-September. The difference between the salt flux from sea ice formation and the salinity increase observed at M1 during June-September then also supports these results and suggests that eddy fluxes must play a key role at the SASSI array.

\section{Transport Associated With the ASC}

[32] Both the water mass variability and the wind forcing in the region will affect the along-shore transport associated with the ASC. Using the velocity time series measured at the mooring array by both the current meters and the ADCPs, we calculate the volume transport perpendicular to the line of the moorings. (The along-shore transport here has been calculated perpendicular to the mooring array (rotating clockwise by $146^{\circ}$ ). However, it should be noted that the array is not parallel with the steepest slope of the topography, and the along-shore direction is also not the same as the angle used for the along-stream current decomposition at M1 (Figure 4). For M1, this along-stream direction was determined using the mean direction of the depth-averaged current during the year of observations (rotating clockwise by $115^{\circ}$; Figure 1a). The along-shore 
(a) Mar

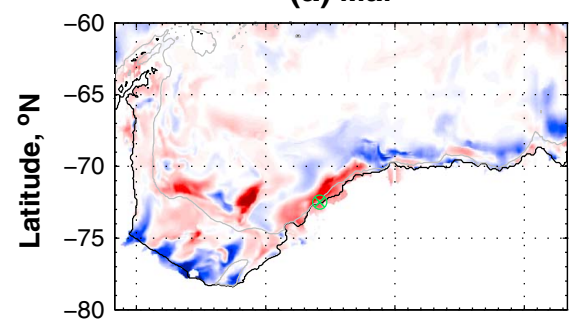

(c) May

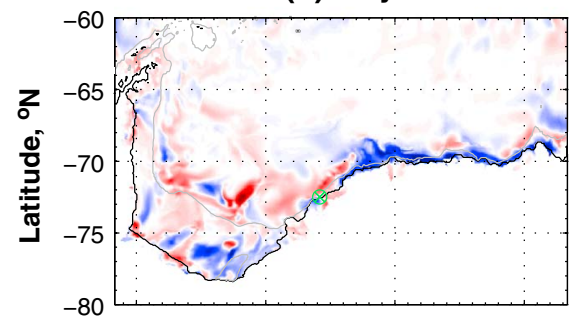

(e) Jul

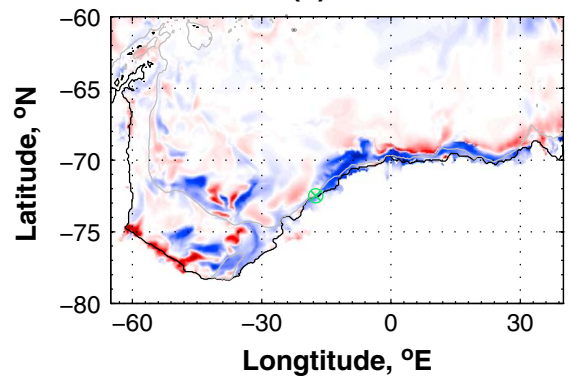

(b) Apr

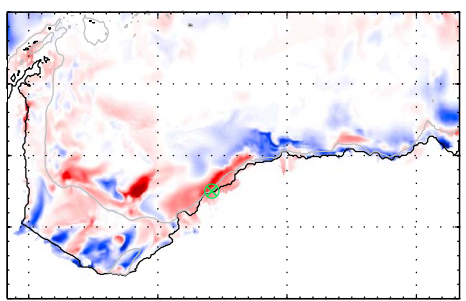

(d) Jun

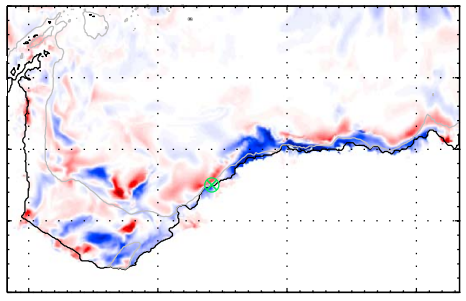

(f) Aug

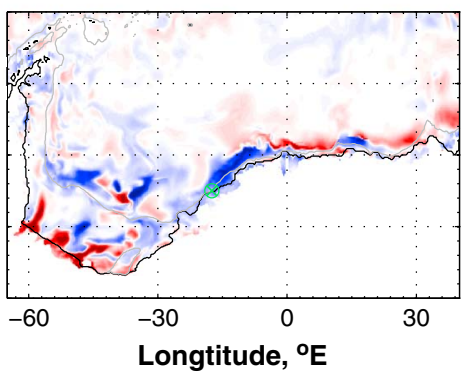

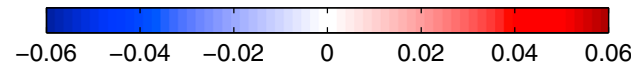

Figure 5. Salinity anomalies from MITgcm simulation for March-August 2009 at $257 \mathrm{~m}$ (model level 19). Anomalies are calculated with respect to the annual mean for 2009. The black contour indicates the coast or ice shelf edge in the model. The gray contour indicates the $1000 \mathrm{~m}$ isobath. Green marker indicates the location of M1 observations.

angle lies between these two values.) At each mooring, we linearly interpolate the velocity between each depth in the vertical and extrapolate the uppermost ADCP current to the surface. The resulting depth-mean currents at the moorings generally vary in phase with each other, indicating that variations in the frontal jet are temporal rather than due to spatial meandering of the jet across the array. Depth-mean currents are interpolated linearly between the moorings, and we assume that the seabed slope is linear between the mooring locations. Figure $3 \mathrm{~d}$ shows a time series of hourly mean cumulative volume transport perpendicular to the mooring array over the year of deployment.

[33] The mean volume transport of the ASC is $7 \mathrm{~Sv}$. At first sight, this is much smaller than the value of $14 \pm 3 \mathrm{~Sv}$ deduced for a single snapshot in March 1995 on the WOCE section A23 [Heywood et al., 1998]. However, the volume transport per kilometer offshore is remarkably similar in the WOCE section to the moored time series in the months of March and April. The moored array encompasses only about one half of the width of the front and omits the transport farther offshore. Because we see no evidence of meandering across the array, we are confident that we have captured the temporal variability of the volume transport of the ASC, if not its absolute magnitude.
[34] There is a seasonal cycle in the volume transport, with maximum values in autumn-winter (May-July) and minimum values in spring-summer (October-December). This seasonal cycle is consistent with that observed farther east at the Greenwich Meridian [Fahrbach et al., 1992; NúñezRiboni and Fahrbach, 2009]. Transport through the array increases during autumn, with peak transport coinciding with increased along-shore wind speeds and negative wind stress curl over the array in late April 2009 (Figures 3c and 3d).

[35] Figure 8 shows the density and wind stress curl conditions at the mooring array, composited on high and low transport conditions (composite limits shown in Figure 3d). For potential density, the greatest difference is seen in the shallow, onshore moorings, at M1-M4. Little change was observed for sensors at M5 or below $1000 \mathrm{~m}$. During periods of high transport, there is steepening of isopycnals on the shelf and above the slope. An increased density gradient is evident between the moorings at $\sim 500 \mathrm{~m}, \mathrm{M} 2-\mathrm{M} 4$. The potential density observed from CTD sections during the deployment cruise in February 2009 is shown for reference as the background contours in Figures $8 \mathrm{a}$ and $8 \mathrm{~b}$. Comparing with these conditions, the isopycnals at M1-M3 are deeper during periods of high transport (Figure 8a). In contrast, during periods of low transport, the isopycnals shoal, and higher 
(a) Jan

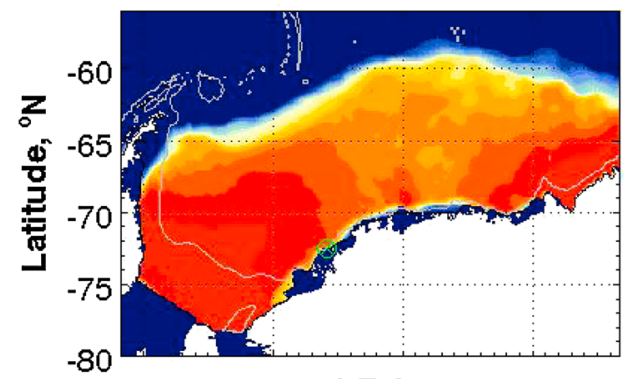

(c) Feb

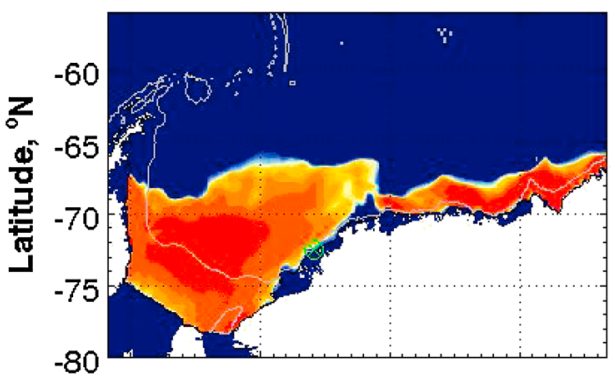

(e) Mar

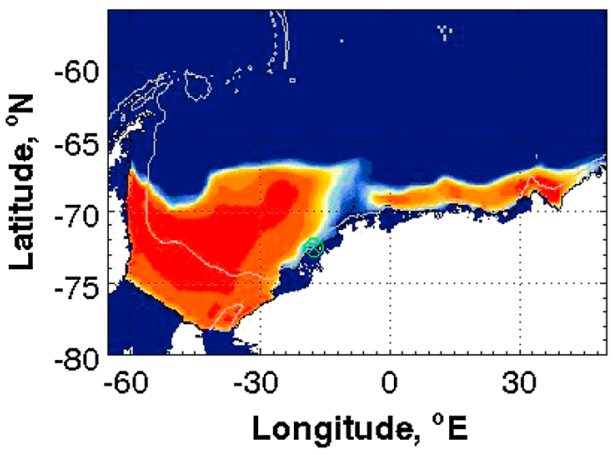

$\begin{array}{lllll}0.2 & 0.4 & 0.6 & 0.8 & 1\end{array}$ (b) Jan

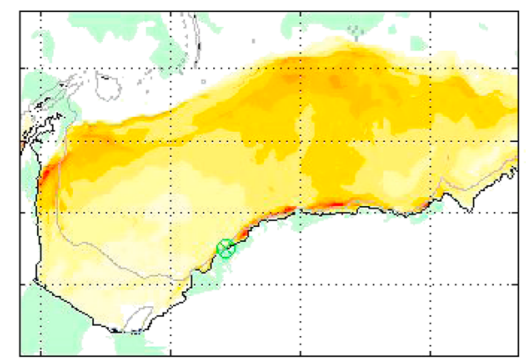

(d) Feb

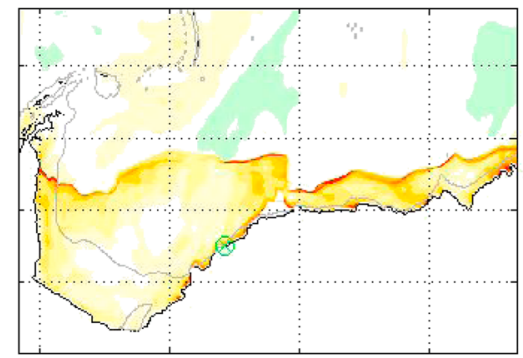

(f) Mar
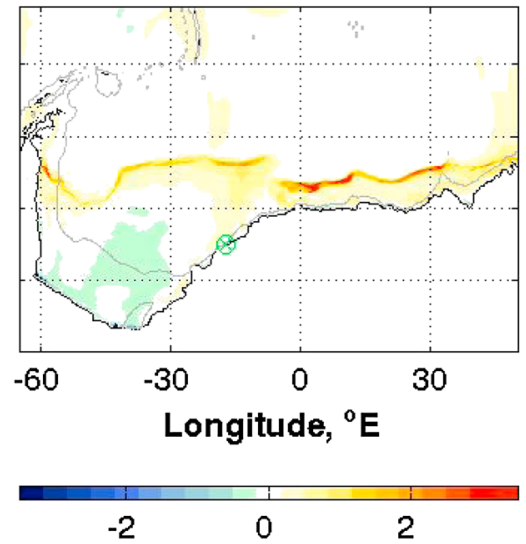

Figure 6. (a, c, e) Sea ice concentration and (b, d, f) total freshwater flux into the ocean $\left[10^{-4} \mathrm{~kg} / \mathrm{m}^{2} / \mathrm{s}\right]$ from the MITgcm simulation for January-March 2009. The black contour indicates the coast or ice shelf edge in the model. The gray contour indicates the $1000 \mathrm{~m}$ isobath. Green marker indicates the location of M1 observations.

densities are found on the shelf (Figure 8b). There is also a smaller density difference between M2 and M4.

[36] The wind stress curl shows increased downwelling along the east coast of the Weddell Sea during periods of high transport, compared with a reduced magnitude of wind stress curl during periods of low transport (Figures $8 \mathrm{c}$ and $8 \mathrm{~d}$ ). This pattern of wind stress curl corresponds with the change in depth of isopycnals observed at the mooring array (Figures 8a and $8 \mathrm{~b}$ ). It is worth noting that the time series and composites of wind stress curl shown in Figures 3d, 8c, and 8d do not include the influence of varying sea ice concentration, which would alter the surface drag on the ocean. Increased sea ice cover may help explain why some periods of negative wind stress curl anomalies do not result in periods of high transport (for example, during September 2009; Figure 3d).

[37] The transport of the ASC is largely barotropic [Heywood et al., 1998], but there is also a baroclinic component due to the cross-shelf density gradient. Following the thermal wind relation, an increase in the cross-shelf density gradient will increase the velocity shear in the water column and, therefore, the baroclinic transport. The timing of water mass variability observed on the shelf is influenced by the wind-driven Ekman transport and along-shore advection (section 4). The retreat and advance of sea ice cover is also a key factor in determining the total freshwater content in the upper layers of the ocean. Results from the MITgcm simulation show that the summer retreat of sea ice leads to a large freshwater anomaly upstream of the SASSI array (Figure 6). The resulting presence of a fresh anomaly on the shelf causes an increased cross-shelf density gradient, with density increasing offshore, and a corresponding increased vertical shear, with the surface-intensified southwestward current decreasing with depth. This shear reduces the depth-integrated transport. The increased ASC transport during autumn must then be primarily caused by the increased sea surface slope resulting from onshore Ekman transport. 
(a) Jan

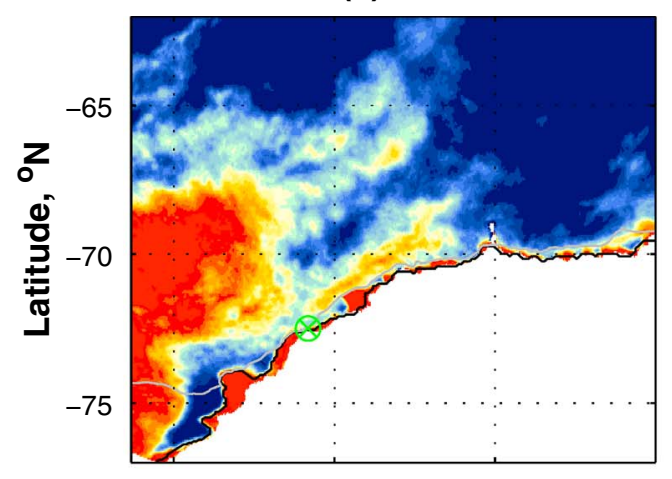

(b) Feb

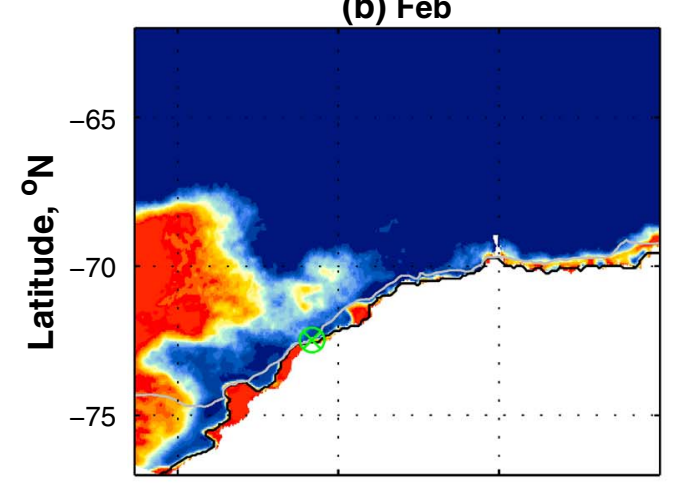

(c) Mar

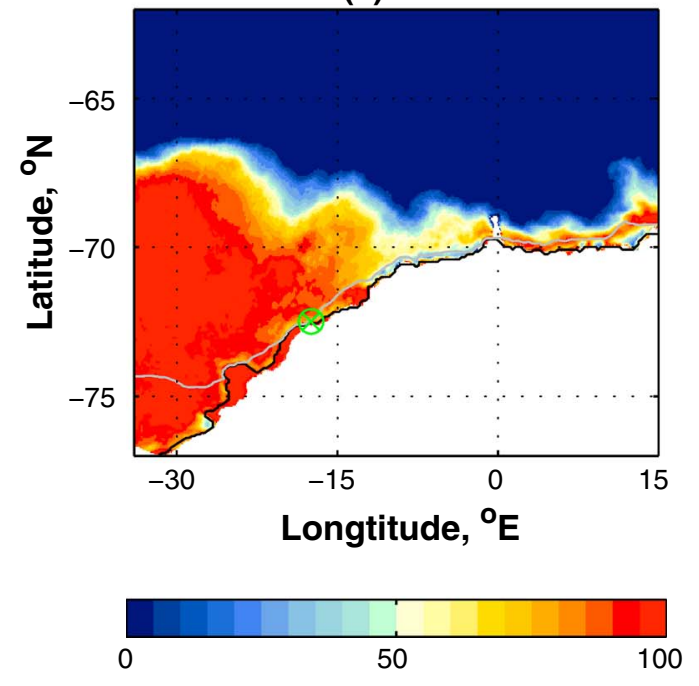

Figure 7. Monthly mean sea ice concentration [\%] for January-March 2009, obtained from Advanced Microwave Scanning Radiometer-EOS (AMSR-E) observations, on a $6.5 \mathrm{~km}$ grid [Spreen et al. 2008]. The black contour indicates the coast or ice shelf edge from GEBCO bathymetry; the gray contour indicates the $1000 \mathrm{~m}$ isobath. Green marker indicates the location of M1 observations.

[38] It is likely that changes in ASC transport will lead to changes in heat and freshwater transport through the mooring array. Depth-averaged, along-stream transport at M1 is correlated with temperature $(-0.22)$ and salinity $(-0.38)$, so as the transport increases, cooler, fresher water is present. While this may be related to heat and freshwater flux anomalies, it is likely that this correlation is strongly influenced by the steepening of isopycnals (Figure 8). Negative correlations are also found for the shallowest sensors at each of the other moorings. The strongest correlations are found at M5, with correlations of about -0.4 for both temperature and salinity. Beneath the pycnocline, transport is positively correlated with both temperature and salinity. However, the changes in density observed at depths $>1000 \mathrm{~m}$ are not as great as those observed at shallower depths (Figure 8). Although this correlation is opposite to that found above the pycnocline, it is still consistent with the deepening of isopycnals at the mooring location (Figure 2a).

\section{Discussion}

[39] Observations from East Antarctica have suggested that on-shelf freshening in autumn may occur every year, due to an autumn peak in wind stress [Ohshima et al., 1996]. The observations of low-salinity shelf waters presented here are consistent with those of Nøst et al. [2011], farther upstream (profiles averaged over $25^{\circ} \mathrm{W}-50^{\circ} \mathrm{E}$ ) during 2008, although the freshening at the SASSI location occurs later in the year (May-June rather than April). Observations beneath the Fimbul Ice Shelf have also shown freshening during March 2010 [Hattermann et al., 2012]. Their freshening was accompanied by warming, whereas the temperature at the SASSI array decreased during autumn and winter (Figure 2a). The freshening observed by Hattermann et al. [2012] in 2010 occurs earlier in the year than that observed by Nøst et al. [2011] and at the SASSI array. During 2010, periods of increased along-shore winds in the eastern Weddell Sea occur earlier in the year (not shown). The increased temperature observed beneath the Fimbul Ice Shelf is then likely related to the timing of wind events; the upper layers that are advected onshore and beneath the ice are likely to have higher temperatures in March than in April-May. Therefore, the timing of increased along-shore winds, relative to the seasonal cycle of surface temperatures, may be vital for correctly simulating the influx of heat into ice shelf cavities.

[40] As the ASF is an almost circumpolar feature [Jacobs, 1991; Heywood et al., 2004], it is likely that advection will influence the seasonal cycle in other shelf regions around the continent. This may occur through the transport of either fresh or saline anomalies, but for the purpose of this study, we focus on the transport of fresh anomalies. Using the MITgcm simulation, we have determined how the mean month of the salinity minimum (average annual cycle for 1981-2010), at the depth of M1 ( 250 m), varies along the shelf break (Figure 9). This indicates which other regions have seasonal freshening that may be strongly influenced by along-shore advection (similar to that observed at the SASSI array). Figure 9 indicates four regions where the minimum occurs later in the year farther westward along the coast, consistent with advection of a fresh anomaly downstream. These four regions are the southeastern Weddell Sea, $35^{\circ} \mathrm{E}-55^{\circ} \mathrm{E}, 140^{\circ} \mathrm{E}-155^{\circ} \mathrm{E}$, and $200^{\circ} \mathrm{E}-225^{\circ} \mathrm{E}$. It is interesting to note that three of these regions are located immediately upstream of AABW formation regions-FilchnerRonne Ice Shelf, Ross Sea, and Adelie Coast. The seasonal cycle presented in Figure 9a is from a 20 year mean, and 
(a) High Transport, Potential Density

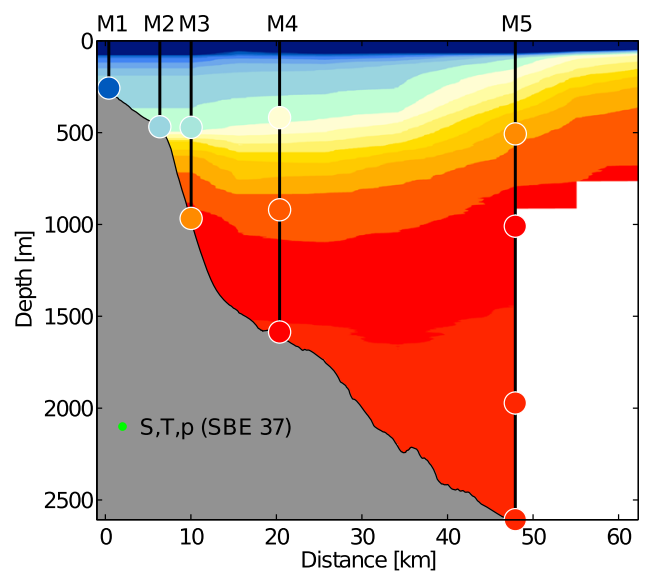

(c) High Transport, WSC

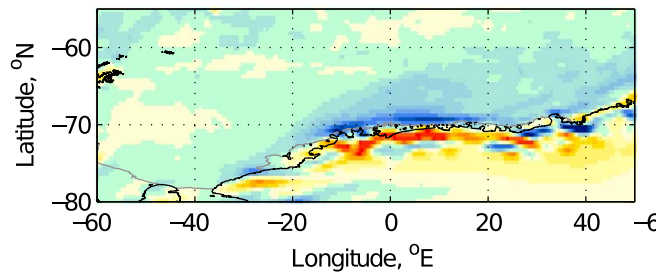

(b) Low Transport, Potential Density

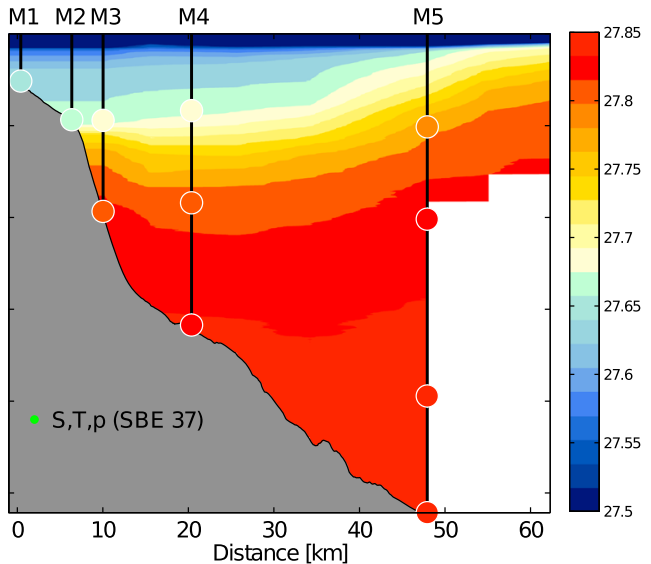

(d) Low Transport, WSC

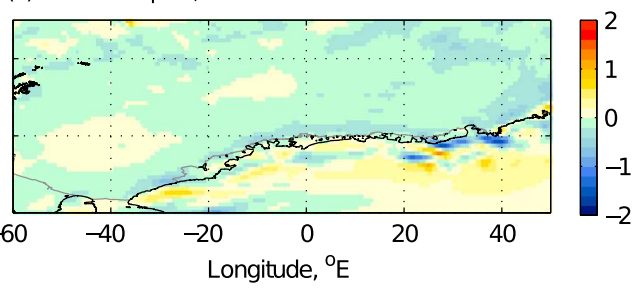

Figure 8. (top) Composite potential density $\left(\mathrm{kg} \mathrm{m}^{-3}\right)$ observed at the mooring array during periods of (a) high or (b) low ASC transport. Background contours indicate the potential density field observed during the deployment cruise (February 2009), for comparison. (bottom) Composite wind stress curl (WSC) $\left[10^{-1} \mathrm{~N} \mathrm{~m}^{-3}\right]$ during periods of (c) high or (d) low ASC transport. Limits of high and low trtransport are shown in Figure 3d.

there will be interannual variations in this timing, as well as the relative importance of the mechanisms responsible. As this study has shown, there are also differences in magnitude between the currents represented in this model and those that have been observed (Figures $3 \mathrm{f}$ and $4 \mathrm{c}$ ). However, this demonstrates that advection is likely to be important for other
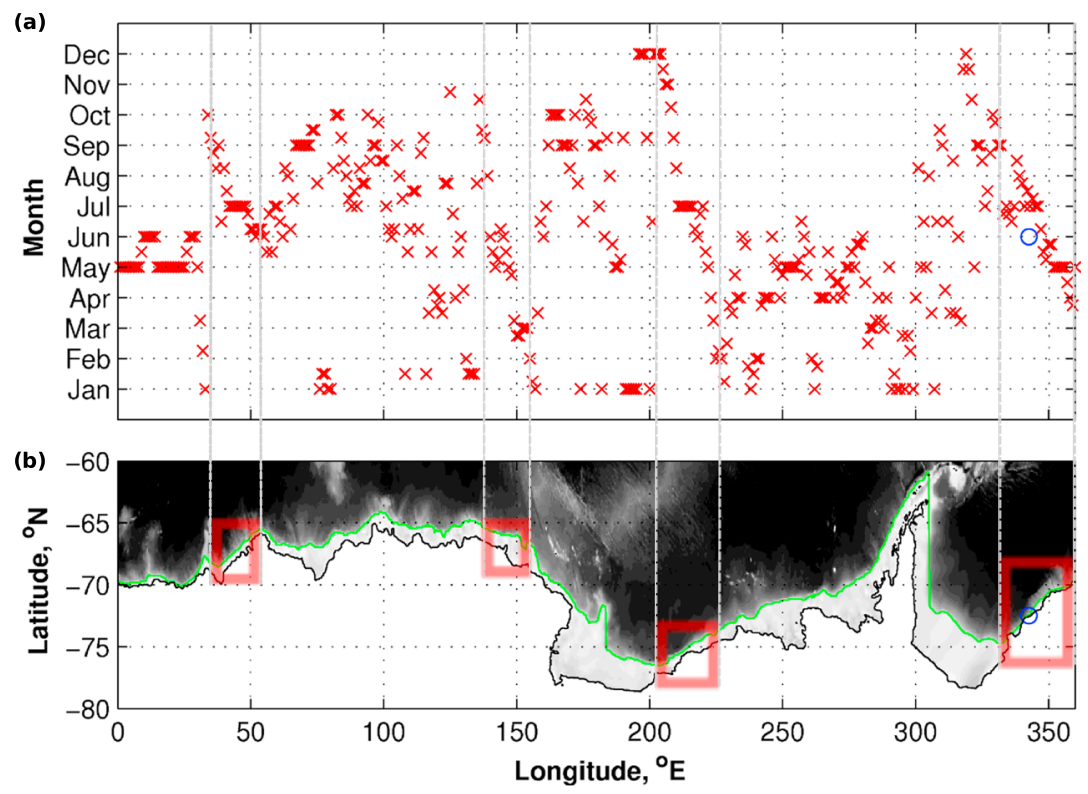

Figure 9. (a) Variation in timing of salinity minimum at $257 \mathrm{~m}$ at the shelf break in MITgcm, averaged over 1981-2010. Results have been binned into $1^{\circ}$ longitude intervals. Blue circle indicates the location of the SASSI array, with minimum salinity in June. (b) Schematic to illustrate regions where along-shore advection is likely to influence the timing of the salinity minimum at $\sim 250 \mathrm{~m}$ depth (gray dashed lines and red boxes). The location of the shelf break around the Antarctic continent, $\sim 500 \mathrm{~m}$, is shown by the green line. Black line shows the coast or limit of the ice shelf. Shading illustrates the bathymetry in the region. 
regions around the continent. Further investigation is needed in order to understand how the relative role of the processes discussed here may differ over both space and time.

[41] Previous observations from the eastern Weddell Sea have shown that the seasonal cycle of the Antarctic Coastal Current is primarily governed by Ekman transport [NúñezRiboni and Fahrbach, 2009]. Increased along-shore winds, as well as an "optimal" sea ice cover, causes peak transport in autumn. This timing is consistent with our observations. Observations from the SASSI array support the suggestion that transport is strongly influenced by Ekman transport, as the peak transport associated with the ASF occurs during the period of increased along-shore winds. However, the ice cover at the SASSI array remains above the optimal value for surface momentum transfer, with concentrations $>90 \%$ during the period of maximum transport. High transport through the array typically coincides with wind stress anomalies that cause downwelling along the eastern coast of the Weddell Sea, increase the sea surface slope, and increase the cross-shelf density gradient. The arrival of a fresh anomaly on the shelf from upstream will also increase the cross-shelf density gradient. As density increases offshore, the along-stream current will decrease with depth, reducing the depth-integrated transport. The increased transport through the array between April and July 2009 must then be caused by an increased sea surface slope.

\section{Conclusions}

[42] Observations from a mooring array across the Antarctic continental shelf and slope have shown the key processes responsible for variability in water masses and transport in the southeastern Weddell Sea. Fluctuations in temperature and salinity throughout the year are linked with variability in wind stress over the array. This causes the deepening or shoaling of the pycnocline, past the depth of the sensors. During autumn 2009, the water mass observed on the continental shelf becomes fresher, reaching a salinity minimum in early June at $\sim 250 \mathrm{~m}$. The freshening begins in late April 2009, coinciding with a strong along-shore wind event and peak in negative wind stress curl. This causes increased mixing, onshore Ekman transport of fresh surface waters, and convergent downwelling on the shelf. A model simulation shows that the salinity minimum observed at the SASSI array is strongly influenced by advection of the previous summer's sea ice meltwater from upstream. This influence of along-shore advection was not included in the Nøst et al. [2011] model, since they consider average properties over a large stretch of coast. However, we show that the addition of this process is key to the correct representation of shelf-water properties at our localized section across the shelf and slope. This process is also likely to influence seasonality in other regions around the continent.

[43] Transport associated with the ASF increases during autumn 2009, with its peak coinciding with the peak in along-shore wind speed, negative wind stress curl, and arrival of the fresh shelf-water anomaly in late April. During the year of observations, periods of high transport are typically associated with negative wind stress curl anomalies along the coast of the eastern Weddell Sea, as well as an increased cross-shore density gradient. Density increasing offshore will increase the vertical shear in the water column, decreasing the southwestward transport. The increased ASC transport during autumn must then be primarily caused by the increased sea surface slope resulting from onshore Ekman transport. The seasonality and mechanisms observed here agree with those presented in previous studies [Núñez-Riboni and Fahrbach, 2009].

[44] Hellmer et al. [2012] found that under a future climate scenario, reduced ice cover in the southeastern Weddell Sea leads to a redirection of the coastal current underneath the Filchner-Ronne Ice Shelf. This increases the transport of warm water into the ice shelf cavity, resulting in a drastic increase of the basal melt rate. It is important that regional climate models are able to accurately represent air-sea-ice interactions in order to predict how the heat and freshwater content on the shelf may change in the future. The model simulation used here shows that along-shore advection plays a key role in determining shelf-water properties, along with freshwater fluxes from seasonal sea ice retreat upstream. Advection is likely to play a key role in determining the seasonality of other regions around the Antarctic continent. An inaccurate representation of these processes can alter the seasonal cycle of temperature and salinity in the ocean. As the timing and strength of alongshore winds varies from year to year in the southeastern Weddell Sea, this will affect the seasonal variability of water masses in this region. Such changes may have large implications for ice shelves in the region and AABW formation farther downstream, which in turn could have impacts on global sea level and ocean circulation.

[45] Acknowledgments. This work was supported by NERC grant NE/E012965/1. We thank the scientists, officers, and crew of the RRS Ernest Shackleton and RRS James Clark Ross for the mooring deployments and recoveries respectively. Thanks to Keith Nicholls for the Weddell seal CTD data and Takeshi Tamura for the salt flux data [further information at http://wwwod.lowtem.hokudai.ac.jp/polar-seaflux/]. We would also like to thank two anonymous reviewers for their constructive comments, which significantly improved this manuscript.

\section{References}

Årthun, M., K. Nicholls, and L. Boehme (2013), Wintertime water mass modification near an Antarctic Ice Front, J. Phys. Oceanogr., 43, 359-365, doi:10.1175/JPO-D-12-0186.1.

Chavanne, C. P., K. J. Heywood, K. W. Nicholls, and I. Fer (2010), Observations of the Antarctic Slope Undercurrent in the southeastern Weddell Sea, Geophys. Res. Lett., 37, L13601, doi:10.1029/2010GL043603.

Fahrbach, E., G. Rohardt, and G. Krause (1992), The Antarctic Coastal Current in the southeastern Weddell Sea, Polar Biol., 12, 171-182.

Fahrbach, E., R. G. Peterson, G. Rohardt, P. Schlosser, and R. Bayer (1994), Suppression of bottom water formation in the southeastern Weddell Sea, Deep Sea Res., 41, 389-411.

Hattermann, T., O. A. Nøst, J. M. Lilly, and L. H. Smedsrud (2012), Two years of oceanic observations below the Fimbul Ice Shelf, Antarctica, Geophys. Res. Lett., 39, L12605, doi:10.1029/2012GL051012.

Hellmer, H., F. Kauker, R. Timmermann, J. Determann, and J. Rae (2012), Twenty-first-century warming of a large Antarctic ice-shelf cavity by a redirected coastal current, Nature, 485, 225-228, doi:10.1038/ nature11064.

Heywood, K. J., R. A. Locarnini, R. D. Frew, P. F. Dennis, and B. A. King (1998) Transport and water masses of the Antarctic Slope Front System in the eastern Weddell Sea, in Ocean, Ice and Atmosphere: Interactions at the Antarctic Continental Margin, AGU Antarctic Research Series, vol. 75, edited by S. Jacobs, pp. 203-214, AGU, Washington, D. C.

Heywood, K. J., A. C. Naveira Garabato, D. P. Stevens, and R. D. Muench (2004), On the fate of the Antarctic Slope Front and the origin of the Weddell Front, J. Geophys. Res., 109, C06021, doi:10.1029/ 2003JC002053.

Heywood, K. J., R. Muench, and G. Williams (2012), An overview of the synoptic Antarctic Shelf-Slope Interactions (SASSI) project for the International Polar Year, Ocean Sci., 8, 1-6, doi:10.5194/os-8-1-2012. 


\section{GRAHAM ET AL.: SEASONAL CYCLE OF ANTARCTIC WATER MASSES}

Jacobs, S. S. (1991), On the nature and significance of the Antarctic Slope Front, Mar. Chem., 35, 9-24.

Losch, M. (2008), Modeling ice shelf cavities in a $\mathrm{z}$ coordinate ocean general circulation model, J. Geophys. Res., 113, C08043, doi:10.1029/ 2007JC004368.

Losch, M. D. Menemenlis, J. M. Campin, P. Heimbach, and C. Hill (2010), On the formulation of sea-ice models. Part 1: Effects of different solver implementations and parameterizations, Ocean Modell., 33(1-2), 129-144, doi:10.1016/j.ocemod.2009.12.008.

Marshall, J., A. Adcroft, C. Hill, L. Perelman, and C. Heisey (1997), A finite-volume, incompressible Navier Stokes model for studies of the ocean on parallel computers, J. Geophys. Res., 102(C3), 5753-5766.

Nicholls, K. W., et al. (2006), Measurements beneath an Antarctic ice shelf using an autonomous underwater vehicle, Geophys. Res. Lett., 33, L08612, doi:10.1029/2006GL025998.

Nicholls, K. W., S. Østerhus, K. Makinson, T. Gammelsrød, and E. Fahrbach (2009a), Ice-ocean processes over the continental shelf of the southern Weddell Sea, Antarctica: A review, Rev. Geophys., 47, RG3003, doi:10.1029/2007RG000250.

Nicholls, K. W., I. Fer, C. Griffiths, B. Huber and P. Robinson (2009b), Report for Cruise ESO33. Second ACES-FOCAS cruise to the southern Weddell Sea, British Antarctic Survey, Cambridge.

Nøst, O. A., M. Biuw, V. Tverberg, C. Lydersen, T. Hattermann, Q. Zhou, L. H. Smedsrud, and K. M. Kovacs (2011), Eddy overturning of the Antarctic Slope Front controls glacial melting in the Eastern Weddell Sea, J. Geophys. Res., 116, C11014, doi:10.1029/2011JC006965.

Núñez-Riboni, I., and E. Fahrbach (2009), Seasonal variability of the Antarctic Coastal Current and its driving mechanisms in the Weddell Sea, Deep Sea Res., 56, 1927-1941, doi:10.1016/j.dsr.2009.06.005.
Ohshima, K. I., T. Takizawa, S. Ushio, and T. Kawamura (1996), Seasonal variations of the Antarctic coastal ocean in the vicinity of Lützow-Holm Bay, J. Geophys. Res., 101(C9), 20,617-20,628, doi:10.1029/96JC01752.

Pritchard, H. D., S. R. M. Ligtenberg, H. A. Fricker, D. G. Vaughan, M. R. van den Broeke, and L. Padman (2012), Antarctic ice-sheet loss driven by basal melting of ice shelves, Nature, 484, 502-505, doi:10.1038/nature10968.

Saha, S., et al. (2010), The NCEP climate forecast system reanalysis, Bull. Am. Meteorol. Soc., 91(8), 1015-1057, doi:10.1175/2010BAMS3001.1.

Spreen, G., L. Kaleschke, and G. Heygster (2008), Sea ice remote sensing using AMSR-E 89-GHz channels, J. Geophys. Res., 113, C02S03, doi:10.1029/2005JC003384.

Stammer, D., K. Ueyoshi, A. Kohl, W. G. Large, S. A. Josey, and C. Wunsch (2004), Estimating air-sea fluxes of heat, freshwater, and momentum through global ocean data assimilation, J. Geophys. Res., 109, C05023, doi:10.1029/2003JC002082.

Talley, L. D. (2003), Shallow, intermediate and deep overturning components of the global heat budget, J. Phys. Oceanogr., 33, 530-560, doi: $10.1175 / 1520-0485(2003) 033<0530$ :SIADOC $>2.0$.CO;2.

Tamura, T., K. I. Ohshima, S. Nihashi, and H. Hasumi (2011), Estimation of surface heat/salt fluxes associated with sea ice growth/melt in the Southern Ocean, SOLA, 7, 17-20, doi:10.2151/sola.2011-005.

Thoma, M., K. Grosfeld, and M. A. Lange (2006), Impact of the Eastern Weddell Ice Shelves on water masses in the eastern Weddell Sea, J. Geophys. Res., 111, C12010, doi:10.1029/2005JC003212.

Visbeck, M., and J. Fischer (1995), Sea surface conditions remotely sensed by upward-looking ADCPs, J. Atmos. Oceanic Technol., 12, 141-149, doi:10.1175/1520-0426(1995)012<0141:SSCRSB>2.0.CO;2. 